\title{
Real-time monitoring and control for high-efficiency autonomous laser fabrication of silicon nanoparticle colloids
}

\author{
Brian Freeland ${ }^{1,2,3} \cdot$ Ronan McCann ${ }^{1,2,4}$ (D) Paul O'Neill ${ }^{1,2,4} \cdot$ Sithara Sreenilayam ${ }^{1,2} \cdot$ Manuel Tiefenthaler $^{5}$. \\ Michal Dabros ${ }^{6} \cdot$ Mandy Juillerat $^{6} \cdot$ Greg Foley $^{2,3} \cdot$ Dermot Brabazon $^{1,2,4}$
}

Received: 26 August 2020 / Accepted: 3 February 2021

(C) The Author(s), under exclusive licence to Springer-Verlag London Ltd. part of Springer Nature 2021

\begin{abstract}
Nanotechnology is a significant research tool for biological and medical research with major advancements achieved from nanoparticle (Np) applications in biosensing and biotherapeutics. For laser ablation synthesis in solution (LASiS) to be chosen by researchers for Np colloid production, the process must effectively compete with chemical synthesis in terms of produced colloid quality and productivity while taking advantage of LASiS benefits in terms of its 'green-synthesis' and single-step functionalisation abilities. In this work, a newly developed integrated LASiS Np manufacturing system is presented including a $\mathrm{Np}$ flow reactor design, an at-line Np size monitoring via $180^{\circ}$ dynamic light scattering, and a UV-Vis spectroscopy system used to estimate colloid concentration and stability. The experimental outcomes are discussed in terms of Np productivity and quality via these at-line measurements from the UV-Vis and DLS systems. The developed instrument was validated via off-line SiNps DLS, UV-Vis and morphology tests via TEM. Ultra-high quality and nanoparticle fabrication rate efficiency was achieved and is reported here.
\end{abstract}

Keywords Nanoparticles $\cdot$ Laser ablation synthesis in solution $\cdot$ Silicon nanoparticles $\cdot$ Additive manufacturing $\cdot$ Dynamic light scattering $\cdot \mathrm{UV}$-Vis spectroscopy $\cdot$ Real-line monitoring

\section{Introduction}

The production of nanomaterials, and nanoparticles (Nps) in particular, has become a topic of great interest recently, with these nanomaterials finding application in areas such as biosensing [1, 2] drug delivery [3], in vitro toxicity tests [4], environmental testing [5], flexible printed electronics [6] and nanomedicine [7-9]. Current commercial synthesis of

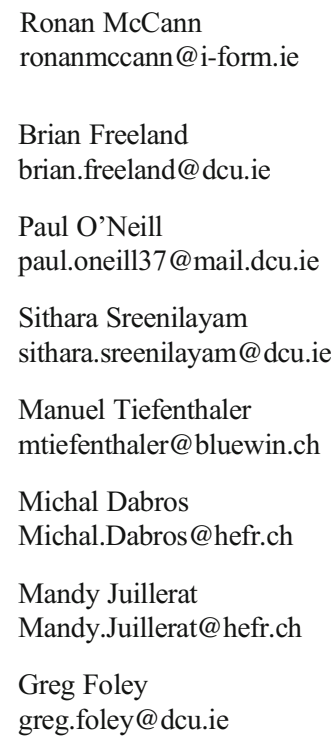

Dermot Brabazon

dermot.brabazon@dcu.ie

1 I-Form Advanced Manufacturing Research Centre, Dublin City University, Glasnevin, Dublin 9, Ireland

2 Advanced Processing Technology Research Centre, School of Mechanical and Manufacturing Engineering, Dublin City University, Glasnevin, Dublin 9, Ireland

3 School of Biotechnology, Dublin City University, Glasnevin, Dublin 9, Ireland

4 National Centre for Plasma Science and Technology, Glasnevin, Dublin 9, Ireland

5 Lucerne University of Applied Sciences and Arts, CH-6002 Luzern, Switzerland

6 School of Engineering and Architecture, HES-SO University of Applied Sciences and Arts Western Switzerland, Bd de Pérolles 80, CH-1700 Fribourg, Switzerland 
nanomaterials relies on chemical reduction methods which are cost-effective for bulk production. However, these chemical techniques use environmentally harmful solvents and reagents, and with a shift in focus towards sustainable practices, alternative routes for $\mathrm{Np}$ synthesis are actively being explored by many research groups. Such chemical synthesised nanoparticles may not be ideal for such biomedical or biopharma applications, where surface purity is an essential requirement [10]. One potential solution to this challenge is the move towards physical techniques such a Laser Ablation Synthesis in Solution (LASiS) [11].

The LASiS technique involves the use of a high-power pulsed laser for the ablation of a solid target immersed in a liquid [12], and this process produces Nps in a liquid as a colloidal solution. In this technique, two shockwaves are expelled from the target material as a result of laser irradiation. These shockwaves propagate through the overlying liquid and the underlying target [13]. The laser irradiation and resulting shockwaves induces heating and ionisation of the target volume, and as a result, a plasma plume is generated and expands into the solvent, producing a Np colloid upon condensation [14]. Compared with chemical synthesis techniques, LASiS produces bare, ligand-free Nps [15]. This allows the produced Nps to be functionalized in a single-step either during production, by choice of solution composition [16], or by post-processing [17, 18]. Recently, our research group has reported the use of these laser synthesised nanomaterials in biomimetic surfaces [19] and biological sensing applications [20]. The advantage of LASiS over competing techniques is that it allows the targeted, costeffective on-demand production of Nps for research purposes. However, to increase productivity, several challenges need to be addressed before LASiS can be adopted in biopharmaceutical and biomedical environments. These include achieving chemical synthesis efficiencies of scale [21] and process validation and monitoring to meet the Food and Drug Administration's (FDA) [22] Quality-by-Design (QbD) framework [10], and more recently the Emerging Technologies Program (2017) [23]. In this work we present a new system developed towards addressing these process challenges. An aim of this work was to build on the extensive development work in the field to date $[24,25]$, by improving LASiS efficiency through moving towards a continuous production process introduced previously [26]. In this paper, a low-power laser system is optimised for LASiS, which would be more suited to provide a turn-key, on-the-bench solution for biopharma research laboratories compared with higherpowered systems [27]. For LASiS to become an accepted Np production process in regulated environments, such as the biopharma industry, it must meet regulations such as the FDA Process Analytical Technology (PAT) guidelines and QbD frameworks. A major component of the $\mathrm{QbD}$ framework is to monitor the critical process parameters in a timely fashion and enact process change in order to ensure the process stays within specifications and control $[10,28]$.
LASiS is currently being developed towards increasing productivity $[15,27,29]$ through applying greater laser power to increase Np yield, at the expense of efficiency and capital costs. To date, there has been limited reports of integrating online sensors [30] or commercial Process Analytic Tools (PAT) into LASiS production systems, leading to slow process characterisation. This poses questions of the readiness for adoption of the technique within regulated industries. Also, from a material development viewpoint, integrated process monitoring would offer the ability to monitor and change these variables at speed, allowing for rapid process characterisation and $\mathrm{Np}$ development. This work examines the development of an onthe-bench production device, suitable for implementation in research laboratories, utilising pico-second $(\mathrm{pS})$ lasers which offer a good compromise between capital cost, low pulse duration and average laser power.

In this work, an integrated LASiS Np manufacturing system, including $180^{\circ}$ DLS to monitor particle sizing and UVVis spectroscopy to estimate colloid concentration and monitor stability, is presented. The intention of this exploration was twofold: (1) to incorporate in-situ process characterisation integrated with process variable control, paving the way towards rapid manufacturing of NPs and (2) to perform real-time single-step product validation. A multi-material polymer additive manufacturing (3D printing) technique was employed to develop the Np synthesis flow-cell reactor, enabling optimisation of Np production efficiency. The developed system was trialled in two regimes: continuous and recirculation production (also known as semi-batch), these production modes were compared with traditional batch production. The trials were performed for silicon Nps (SiNps) production, due to its biocompatibility, active surface properties, distinctive photoluminescence and their extensive use in biomedical and biopharma applications [1, 3, 5, 7]. The results of these trials are described and discussed in terms of SiNp productivity and quality via on-line measurements from the UV-Vis and DLS systems. As a means of instrument validation off-line SiNps DLS, UV-Vis and morphology analysis were performed via transmission electron microscopy (TEM).

\section{Experimental section}

\subsection{Description of the system}

The autonomous Np production system developed is shown in Fig. 1. The laser source employed for development constituted a low-power micro-machining Nd:YAG laser (WEDGE HF 1064 , BrightSolutions, Italy) with a pulse width of 700 ps. The laser beam was rastered using a 2D scanning galvanometer (Raylase SS-12) at variable linear speeds moving in an Archimedean spiral pattern over the surface of the target material. The target was maintained in the beam-waist via a $1 \mathrm{D}$ - 


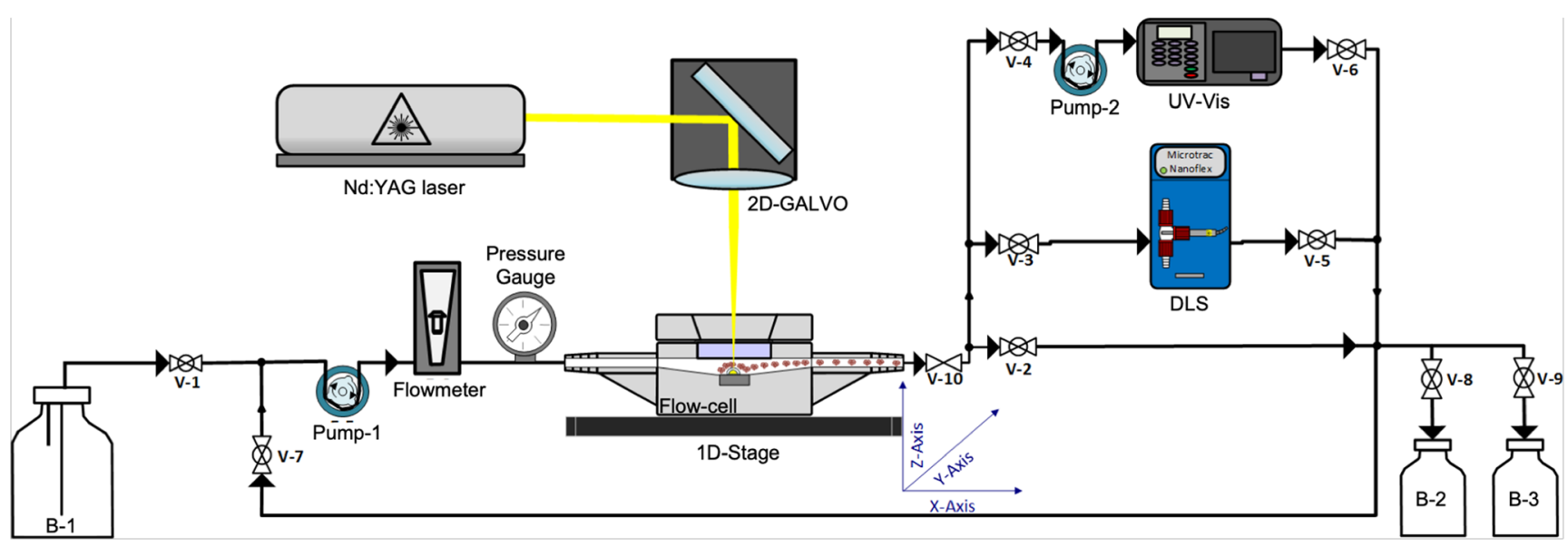

Fig. 1 Nanoparticle fabrication system consisting of a laser, flow cell reactor, peristaltic pump, at-line DLS and UV-Vis, and automated flow circuit control elements

nanopositioning stage (M-404 4PD, PI, Germany), maintaining a spot size of $100 \mu \mathrm{m}$ in diameter. The custom-designed 3D-printed flow-cell was fixed horizontally onto the stage. The reservoir (B-1) contained degassed solvent pressurised via a remotely controlled variable speed peristaltic pump (Isamatic MCPV510, Millipore Ltd) with flow-rates from 10 to $400 \mathrm{ml} / \mathrm{min}$. Operating pressure in the flow-cell was controlled using a Hoffman tubing clamp (V-10) mounted at the exit of the flow-cell. Gauge pressure (bar) was measured via an analogue pressure gauge. Fluid flow in the system was controlled via " 10 remotely operated $1 / 4$ " solenoid valves (V-1 to V-10). The flow circuit tubing consisted of $2 \mathrm{~mm}$ ID PTFE piping. Colloids were collected in a glass bottle (B-2). A waste reservoir (B-3) was employed for system cleaning in place (CIP) and degassing. The pipe network was designed to accommodate selectable recirculation or continuous production, allowing for different production modes and fluid conditions to be tested automatically.

\subsection{Flow-cell design}

The ablation flow-cell (Figs. 1 and S2) was designed to enable production from small volumes $(\mathrm{ml})$ to large volumes of multi-litre colloids. The design enables laminar flow conditions at the ablation site and helps to reduce masking effects of the cavitation bubble [31], plume occlusion [32], and particle aggregation [15] and reducing the formation of eddy currents. An iterative design process was performed using additive manufacturing via $3 \mathrm{D}$ printing [33] to rapidly produce new flow-cell prototypes (see Fig. S1). These were fabricated using a Stratasys Objet260 Connex 1 material jetting printer employing dual-material print with VeroWhitePlus (RGD835) photopolymer (65 shore D) [34] selected for the chamber structure due to its comparable material properties to Teflon PTFE (hardness 55 shore D) [35], and soft photopolymer TangoBlack (FLX973) used for the top-plate gasket ensuring a hermetic seal for the system. The inlet for the flow-cell geometry is a diffuser-nozzle design, as seen in Fig. 2.

A series of five prototypes were produced before the optimum design was achieved (see Figs. S1 and 3). The design methodology considered the following mechanical and chemical requirements: liquid flow performance, hermetic sealing of the flow-cell, fluid pressure resistance, low Nps adhesion to flow-cell surface and minimisation of the internal wetted volume to allow for measurable Nps concentrations and high flow velocities if required. A starting specification for the flow-cell design was to ensure laminar flow at the ablation site. A secondary concern was to minimise the volume in the flow network surrounding the flow-cell by minimising the inlet pipe diameter to the flow-cell $\left(D_{1}\right.$, Fig. 2). This would contribute to a lower dilution factor of nano colloid in the solvent which also helps ensure that the $\mathrm{Np}$ colloid provides a signal above the limit of detection (LOD) of the at-line PAT tools, during general operation in continuous and recirculation modes.

A minimum dimension for the flow-cell inner diameter $\left(\mathrm{D}_{2}\right.$, Fig. 2) at the ablation site was defined by the target material geometry selected. Due to cost, availability and laser scanning considerations, material rods outer diameter $\left(\mathrm{D}_{\mathrm{t}}\right)$ was set at 8.5 $\mathrm{mm}$. Given the dimensional specifications, the angle of the diffuser cone $(\theta)$ would be critical to produce a developed, laminar flow. Venturi nozzle geometry specifications were chosen as a design template for the flow-cell due to the streamlined flow and low-pressure losses exhibited, during Venturi nozzle operation. A cone angle in the range of $5-15^{\circ}[36]$ was used to produce a streamlined flow within the nozzle The fluid layer height between the target and glass laser window was optimised at $4 \mathrm{~mm}$, minimising energy losses due to absorption of the solvent while ensuring no plume/glass interaction [21]. The beam depth of focus $(<1.5 \mathrm{~mm})$ was such that there was no possibility of laser-window ablation. The window was 
Fig. 2 A top-down layout of the difuser-nozzle flow-cell, featuring target diameter $\left(D_{t}\right)$, inlet pipe diameter $\left(\mathrm{D}_{1}\right)$, internal flow-cell diameter at target $\left(\mathrm{D}_{2}\right)$ and diffuser angle $(\theta)$

positioned at an angle offset from the normal $\left(3^{\circ}\right)$ to deflect away any back reflections of the laser beam.

The third prototype (Fig. S1c) was designed to incorporate a borosilicate N-BK7 AR-coated laser window. The laser window had a transmission wavelength ranges of 523 to $532 \mathrm{~nm}$ and 1047 to $1064 \mathrm{~nm}$, a high damage threshold $\left(10 \mathrm{~J} / \mathrm{cm}^{2}\right)$ and low laser absorption (> 92\% transmission at $532 \& 1064 \mathrm{~nm}$ ). The final prototype (Figs. 3 and S1d), included an EPDM Oring to allow for operation at higher liquid pressures ( $>4$ bars). The O-ring also offered better chemical resistance to solvent than the 3D printed tango black gaskets.

\subsection{Autonomous platform development}

The connectivity and control of the developed system is shown in Fig. 4. It is composed of a USB 2.0 hub (Belkin, USA) linking the control PC to the UV-Vis, micro-position stage, laser and DLS systems. A National Instruments CompactRIO (cRIO-9041) industrial controller was used to manage the fluid control valves and the pump control while an industrial Ethernet switch (Beckhoff Gmbh, Germany) was used to manage data connectivity with the DLS data files along with PC connection to the NI CompactRIO.

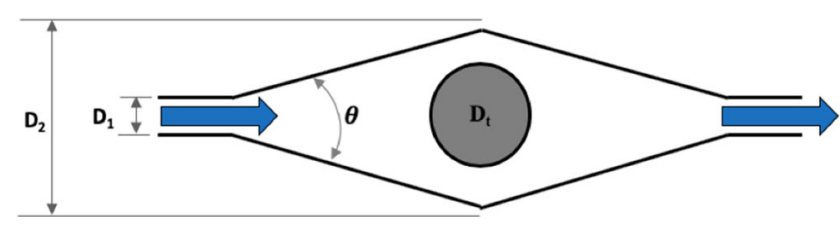

The at-line DLS measurement was implemented with a NANO-flex ${ }^{\circledR} 180^{\circ}$ DLS Size, Microtrac Ltd., via a by-pass loop as DLS measurements must be taken under static fluid conditions, i.e., fluid movement only due to Brownian motion [37]. During measurement, the by-pass loop was isolated from the main loop by closing valves (V-3 \& V-5, see Fig. 1). After the produced colloid was directed to the at-line measurement location, a time delay of $30 \mathrm{~s}$ was implemented to ensure that the colloid had stabilised prior to measurement. During $\mathrm{Np}$ fabrication, continuous mixing was performed between the by-pass loop and the main loop by alternating the control valves to enable near real-time measurement of the colloid. At-line UV-Vis measurement was implemented via a Libra S22 UV-Vis spectrophotometer (Biochrom Inc., USA) including an $80 \mu \mathrm{l}$ quartz flow-cell cuvette $(10 \mathrm{~mm})$ and in-line peristaltic pump sipper system (Biochrom Inc., USA). Automatic clean-in-place (CIP) flush cycles were performed on both measurement loops at process initialisation, during the liquid fill stage and post-Np fabrication. Baseline measurements were taken at test initialisation for both instruments.

Control and monitoring software was developed in National Instruments LabVIEW 2017 programming environment (see Fig. S3). Bloomy controls [38] and National
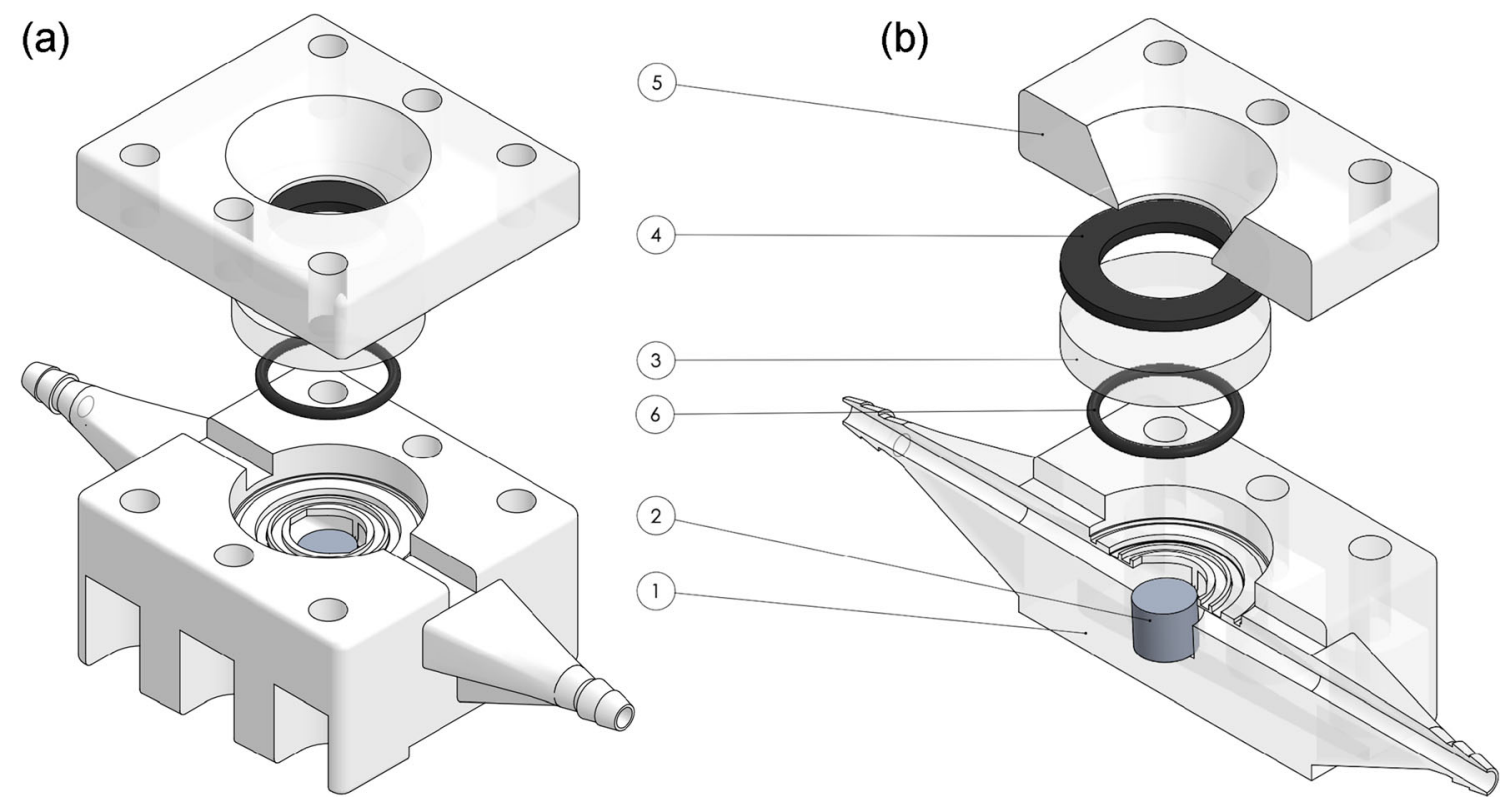

Fig. 3 Schematic (a) and cross-section (b) of the Np fabrication flow-cell design comprising of base (1), target material (2), laser window (3), gasket (4), top-plate (5) and O-ring (6) 


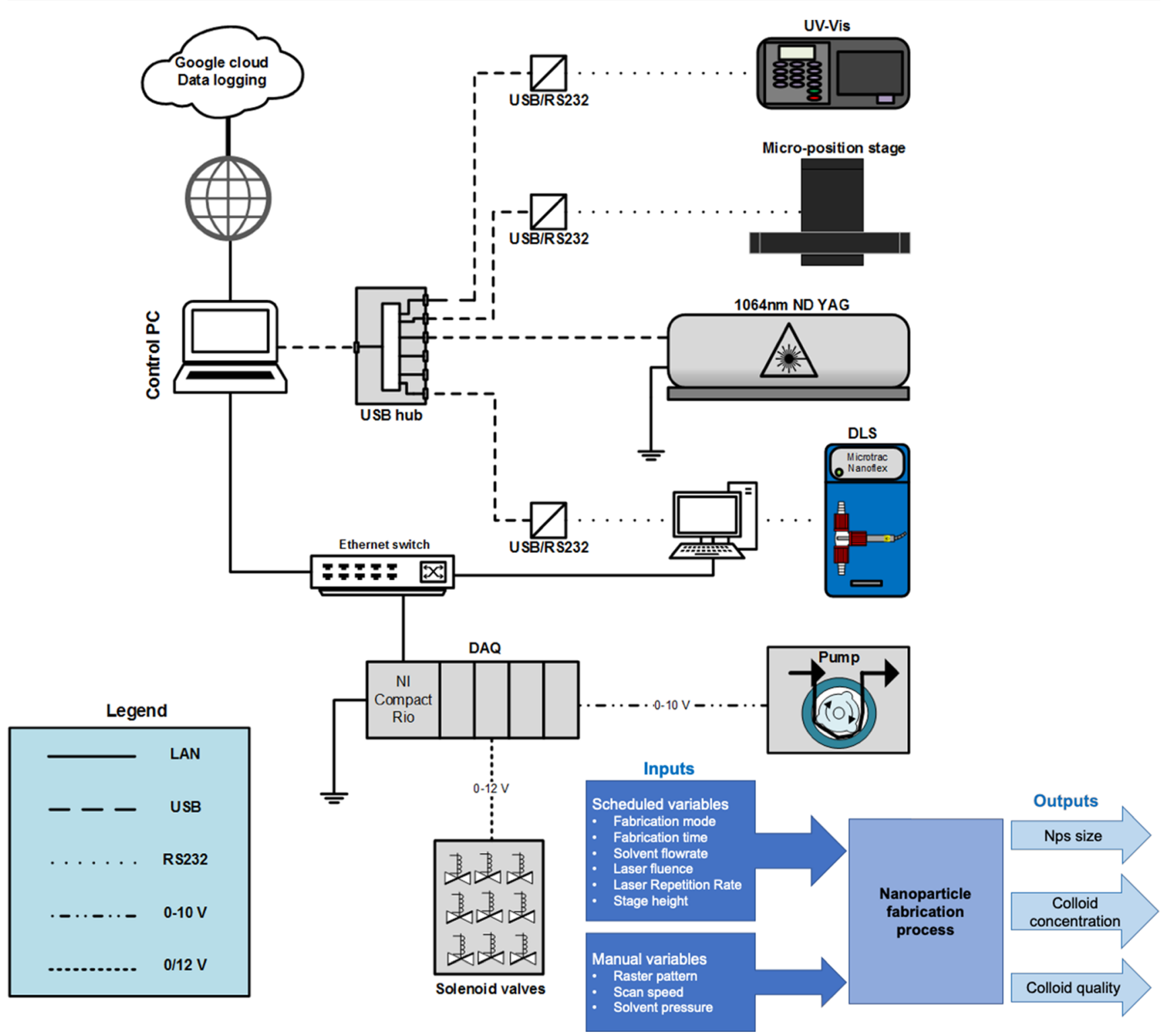

Fig. 4 Nanoparticle manufacturing control platform consisting of production and monitoring hardware connected via serial (RS232), digital (USB and Ethernet) and analogue protocols (0-10, 0/24 VDC). Inset: Nps fabrication system process schematic

Instruments Style Guidelines [39] were incorporated into the design methodology of the user interface and code development. All instrumentation was programmed to be controlled directly in the software as well as via automatic test scripts, described in the flow diagram (Fig. 4, inset). A range of process parameters were controlled directly by the software including laser fluence, repetition rate, solvent flowrate, stage height and fabrication mode (continuous or recirculation). Individual operational system states were selectable including $\mathrm{Np}$ production, measurement, clean-in-place, solvent-fill and data post-processing. Other parameters were manually controlled with user commands and confirmation requests programmed to be sent by the control GUI such as: beam scan- speed, raster pattern, flow-cell pressure and laser wavelength (laser system dependent).

\subsection{Materials and target preparation}

Silicon was chosen as the material for testing and development of the fabrication system due to its availability, biocompatibility and its applications towards the biomedical and biopharma industries including drug delivery [40] and biosensing [41]. As a means to thoroughly test the applicability of the production system in different modes and determine the effectiveness of at-line process monitoring, trials were performed in continuous and recirculation modes, as introduced 
in previous work [24, 42]. The laser parameters used for all SiNps production tests are as follows: fluence $=1.83 \mathrm{~J} / \mathrm{cm}^{2}$, pulse energy $=147 \mu \mathrm{J}$, pulse duration $=700 \mathrm{ps}$, repetition rate $=10 \mathrm{kHz}$, spot diameter $=100 \mu \mathrm{m}$, liquid flowrate $=10-170$ $\mathrm{ml} / \mathrm{min}$, and scan speed $=2 \mathrm{~mm} / \mathrm{s}$. Continuous and recirculation $\mathrm{Np}$ production modes were tested and compared with the standard batch technique. Under batch (Fig. 5a) configuration, the target was placed in a glass vial with $4 \mathrm{ml}$ of deionised (DI) water. During continuous ablation (Fig. 5b), the target was placed in the custom-designed flow-cell with fresh, degassed DI water flowing over the ablation site. Also the recirculation flow (Fig. 5c), comprised of a closed-loop piping system where piping contained an internal process volume of $83 \mathrm{ml}$ of liquid continuously recirculated within the flowcell for a set time. All tests were performed in triplicate.

Si rods $(99.998 \%$ metals basis, Alfa Aesar, $\varnothing=8.5 \mathrm{~mm}$ ) were cut into 4-mm slices, and these plate targets were then mechanically polished using P1200 Si carbide abrasive sheets before each test. For batch production, the target was immersed in $4 \mathrm{ml}$ of ultrapure degassed DI water in a glass vial such that there was $4 \mathrm{~mm}$ of DI water above the top of the target. Initial tests confirmed that the liquid height above the target was sufficient to avoid liquid breakdown effects. For continuous and recirculation ablation, the target was mounted within the centre of the flow-cell reactor with the top of the target surface parallel to the flow-cell base. There was a constant flow of degassed DI water above the target.

\section{Results and discussion}

\subsection{Continuous production}

Continuous mode $\mathrm{Np}$ production was evaluated in terms of productivity, efficiency, quality of colloids produced and measurement reliability of the at-line PAT tools installed. The SiNps production within the flow-cell is illustrated in

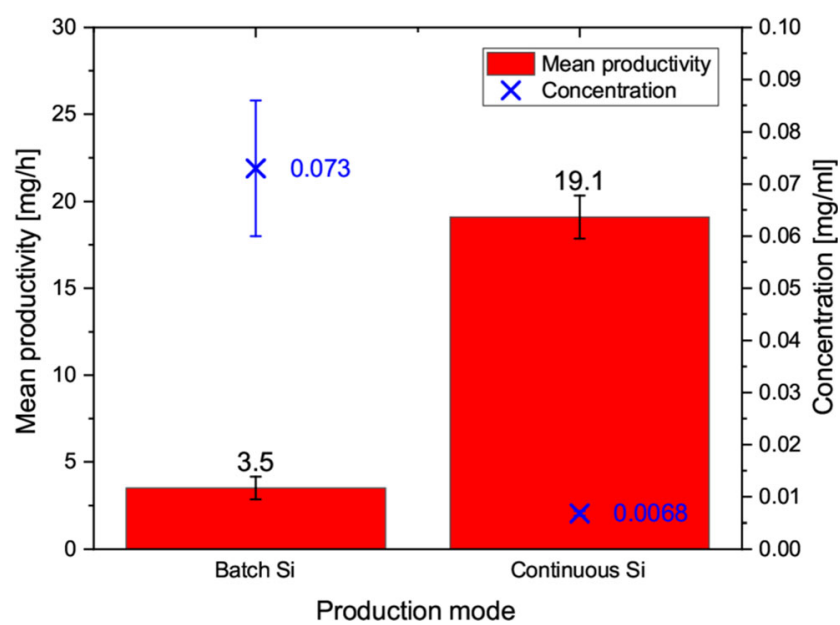

Fig. 6 Mean productivity for SiNp production in batch and continuous modes, with $50 \mathrm{ml} / \mathrm{min}$ flowrate and 0.5 bar gauge pressure, fluence $=$ $1.83 \mathrm{~J} / \mathrm{cm}^{2}$, Repetition rate $=10 \mathrm{kHz}$ determined via gravimetrical measurements $(n=3)$

Fig. S2 in supporting documentation. As expected, continuous mode provides substantially higher $(\times 5) \mathrm{Np}$ productivity $(19.1$ $\mathrm{mg} / \mathrm{h}$ ) compared with batch mode $(3.5 \mathrm{mg} / \mathrm{h})$ (Fig. 6). Continuous production proved to have a low process variation, with a $95 \%$ confidence interval of $1.2 \mathrm{mg} / \mathrm{h}$ from the mean for the 15-min tests. The drawback of the continuous flow system is a reduction in SiNps concentration in the colloid to 6.8 from $73 \mathrm{mg} / \mathrm{L}$ for the batch process. However, 6.8 $\mathrm{mg} / \mathrm{L}$ is an acceptable concentration for most biomedical applications such as DNA tagging [28], allowing Nps produced in this way to be used in single-step functionalisation for biomarker development.

The efficiency of the LASiS processes is described by the 'power-specific productivity' (mg/Wh), which was determined as $12.9 \mathrm{mg} / \mathrm{Wh}$ for the Si tests performed. The state of the art research productivity and efficiencies are reported with gold $\mathrm{Au}$ ), where Wagener et al. [29] reported a production efficiency of $16.2 \mathrm{mg} / \mathrm{Wh}$, using a 500-W ns laser system (a)

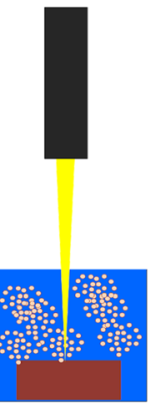

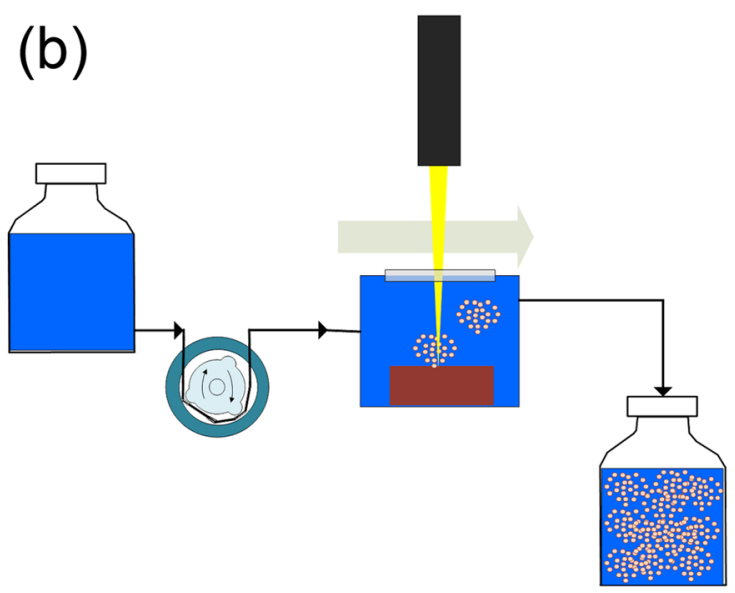

Fig. 5 System schematic of (a) batch, (b) continuous and (c) recirculation production modes

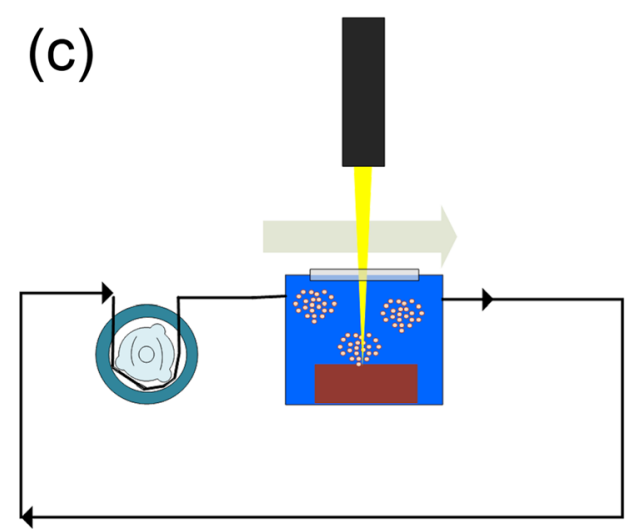


at the Nd:YAG fundamental wavelength for $60 \mathrm{~min}$, and recently by Dittrich et al., [27] who reported a productivity of $37.8 \mathrm{mg} / \mathrm{h}$ and an efficiency of $6 \mathrm{mg} / \mathrm{Wh}$ for a short test (linear extrapolation of $10 \mathrm{~s}$ test) using a similar power laser system $(<10 \mathrm{~W}, 1064 \mathrm{~nm})$ described in this work. The highest production efficiencies previously reported for silicon is $3.63 \mathrm{mg} /$ Wh, reported by Kudryashov et al [43]. Where a high-

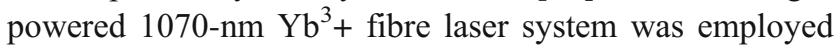
producing pulse energies of $1 \mathrm{~mJ}$ at a repetition rate of $20 \mathrm{kHz}$ [43]. The productivity test results achieved in this work are higher than any previously reported and exceed the highest production efficiency for SiNps reported date [43]. The results achieved approach the current highest production efficiencies reported for $\mathrm{Au}$, a material that possesses a higher absorption coefficient than $\mathrm{Si}$ at $1064 \mathrm{~nm}$ [44]. These are encouraging results for the developed system, providing high $\mathrm{Np}$ production efficiencies compared with the best-in-class medium and high-power laser systems reported to date.

The efficiency of the system can be attributed to a number of factors; firstly the removal of irradiation shielding effects due to the efficient removal of Nps, microbubbles and debris from the irradiation site as a result of efficient laminar flow within the flow-cell [29]. The continuous liquid flow reduces the possibility of liquid breakdown and bubble accumulation due to thermal build-up in the colloid [45]. Temporal avoidance of the cavitation bubble occurred due to low pulse overlap at 10 and $20 \mathrm{kHz}$ repetition rate for the same scanning speed, leading to more efficient ablation [31]. The cavitation bubble lifecycle was reported to range between 150 and 300 $\mu$ s [46], depending on pulse energy. The time-span for the primary bubble collapse to occur can be less than $100 \mu \mathrm{s}$ [30]. Thus, at $10 \mathrm{kHz}$ repetition rate, for low pulse energies used in this work $(147 \mu \mathrm{J})$, temporary avoidance of the entire cavitation bubble, or at least the primary bubble would be expected, contributing to unrestricted irradiation of the target, and hence high production efficiency.

Another contributing factor to high production efficiencies was the relatively low colloid concentration in the process fluid. This low concentration would reduce the possibility for $\mathrm{Np}$ concentration gradients at the ablation site [27], also reducing colloid masking effects. Thermal effects may also be contributing to ablation efficiency. Increasing the bulk temperature of $\mathrm{Si}$ increases its linear absorption coefficient at $1,064 \mathrm{~nm}$ [47] and in doing so, reduces the ablation threshold for $\mathrm{pS}$ laser systems [48]. It has been seen that the Si lattice will increase in temperature upwards of $400{ }^{\circ} \mathrm{C}$ by ps irradiation $(>2 \mathrm{ps})$. As a small interpulse distance $(0.2 \mu \mathrm{m})$ was employed, beam overlap will occur. Due to this overlap, it is expected that local heating of the target material would arise, lowering the ablation threshold for the next pulse, increasing the material mass removal rate.

Changing the flowrate affects the concentration of the colloid and possibly could change productivity by using liquid flow to remove masking agents from the ablation site, as discussed previously. A range of flowrates have been implemented in literature ( 10 to $500 \mathrm{ml} / \mathrm{min}$ ), depending on the application and laser power $[49,50]$. To this end, the viability of UV-Vis spectroscopy as a monitoring tool under a selection of DI water flowrates was evaluated while producing SiNps, as illustrated in Fig. 7. As expected, the highest absorption, thus colloid concentration, was attained at $10 \mathrm{ml} / \mathrm{min}$ flowrate $(0.32$ A.U. abs. at $400 \mathrm{~nm}$ ), with the highest flowrate, 170 $\mathrm{ml} / \mathrm{min}$, tested producing the lowest concentration colloid $(0.05$ A.U. at $400 \mathrm{~nm})$. The absorbance spectra acquired are in agreement with Bagga et al. [20] as representative of a SiNps colloid immersed in DI water. Thus, for the pulse energy $(147 \mu \mathrm{J})$ and fluid flowrates (10 to $170 \mathrm{ml} / \mathrm{min}$ ) tested at-line UV-Vis measurement can characterise colloids produced without the need for prior concentration steps.

As a demonstration of the production system suitability, the colloid size distribution was measured with DLS both during production (at-line) and post-filtration (offline). The results of the measurement are displayed in Fig. 8. Off-line samples were filtered via $0.2 \mu \mathrm{m}$ Millipore vacuum disk filters. The at-line samples displayed a bi-modal peak, possibly due to macroparticles remaining in suspension due to recirculation flow prior to measurement. The off-line filtered sample possessed a size distribution peak at $74.6 \pm 40$ $\mathrm{nm},(2 \sigma)$. The SiNps size distributions reported in this work are similar to those published by Intartaglia et al. $[17,51]$ displaying a shoulder at $500 \mathrm{~nm}$ and a broad continuous band within the range of 220 to $900 \mathrm{~nm}$.

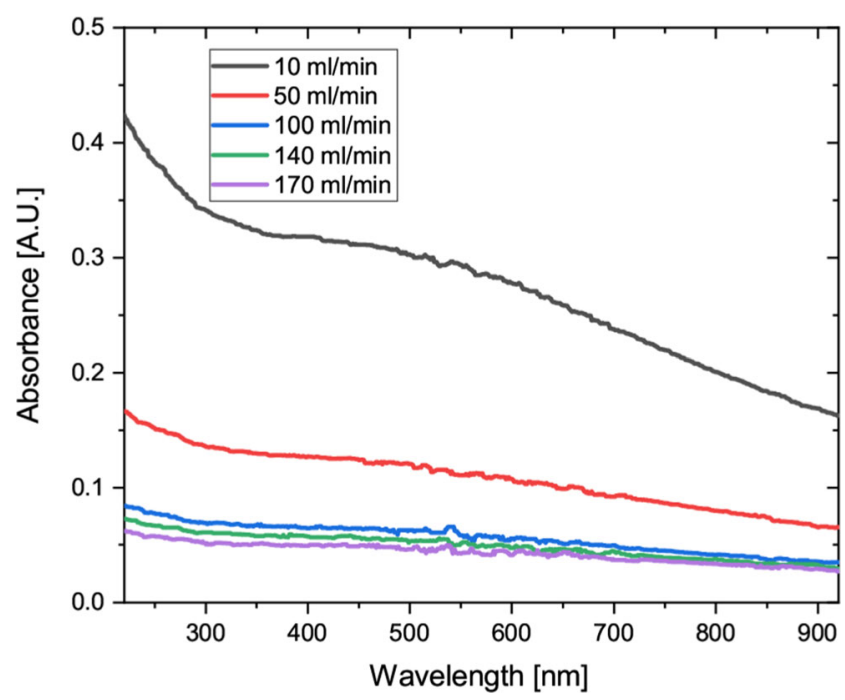

Fig. 7 UV-Vis spectra of continuously produced SiNps colloids for flow rates from to $170 \mathrm{ml} / \mathrm{min}$, fluence $=1.83 \mathrm{~J} / \mathrm{cm}^{2}$, repetition rate $=10 \mathrm{kHz}$ 


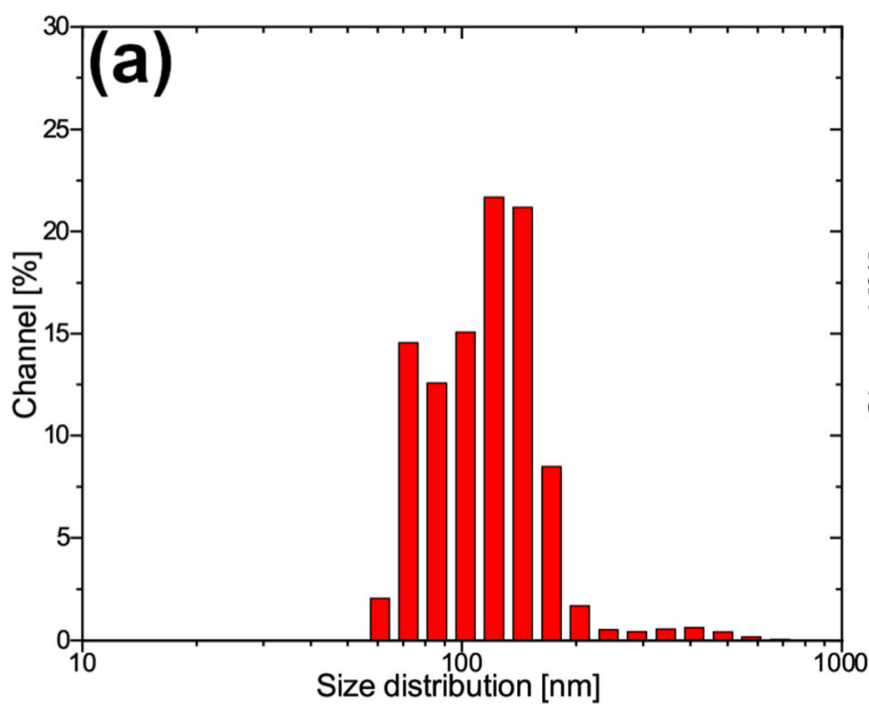

Fig. 8 DLS size distributions of SiNps colloid produced at a flow rate of $50 \mathrm{ml} / \mathrm{min}$ measured at-line (a) and off-line (b). At-line monitoring displaying a bi-modal distribution, peak 1 at $119 \pm 51 \mathrm{~nm}$, (74\% colloid

\subsection{Recirculation production}

The recirculation mode can be utilised to produce colloids to high concentrations allowing for 'concentration on-demand' production. The recirculation mode could also be used to test laser parameter selection, as recirculation time can be increased in order to provide an acceptable measurement resolution for the at-line measurement tools. Additionally, as the flow-cell ensures laminar flow at the irradiation site, particle photo fragmentation could be studied in recirculation mode. Firstly, the productivity performance of the production modes was evaluated. Figure 14 shows results for a series of recirculation production tests, up to $60 \mathrm{~min}$ in length.

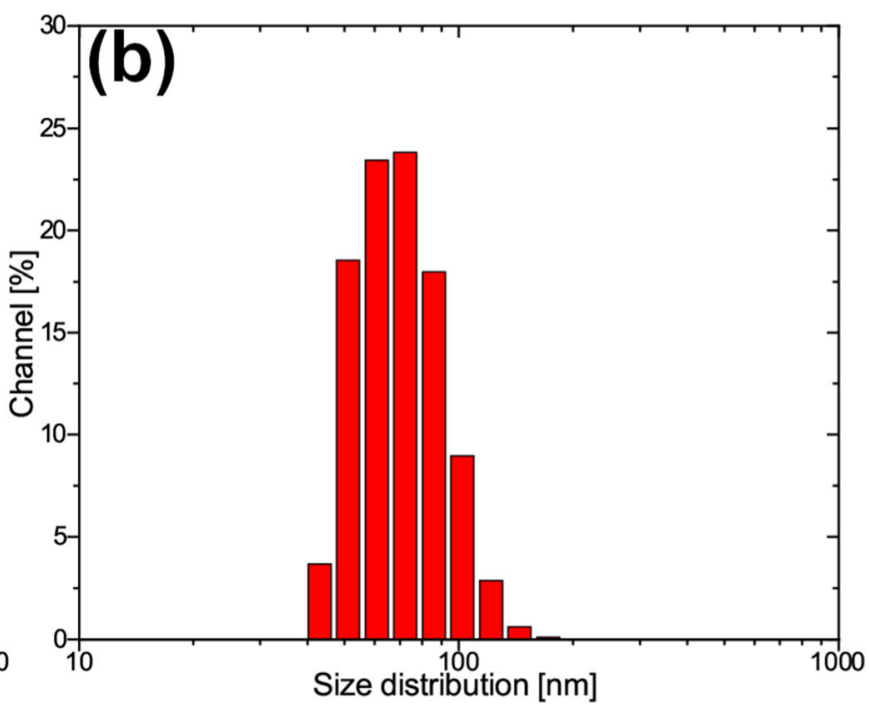

volume) peak 2 at $70 \pm 15 \mathrm{~nm}$ ( $26 \%$ colloid volume), and (b) off-line after $0.2 \mu \mathrm{m}$ filtering the colloid, peak at $74.6 \pm 40 \mathrm{~nm}$

As the recirculation mode is closed-loop, no off-line samples can be taken until the end of the test. Therefore, tests were stopped after 1, 7, 15, 30 and 60 min with gravimetrical ablated mass measurements taken at the end of the test. A recirculation solvent flowrate of $140 \mathrm{ml} / \mathrm{min}$ was selected for all tests. A low process variance was observed for the productivity, with confidence intervals ranging between 7.03 to 0.31 $\mathrm{mg} / \mathrm{h}$ as the mean ablation time increased. The process productivity is in agreement with Beer-Lambert law; as the Nps concentration increases exponentially, they mask the target from laser irradiation. Thus, the productivity is subject to a logarithmic decline from initial high production rates of 34 to $7 \mathrm{mg} / \mathrm{h}$ (Bradley model, $y=-13.21 \times \ln (0.14 \times \ln (\mathrm{x}))$ adjusted $\mathrm{R}^{2}$ of 0.995$)$ as seen in Fig. 9a.
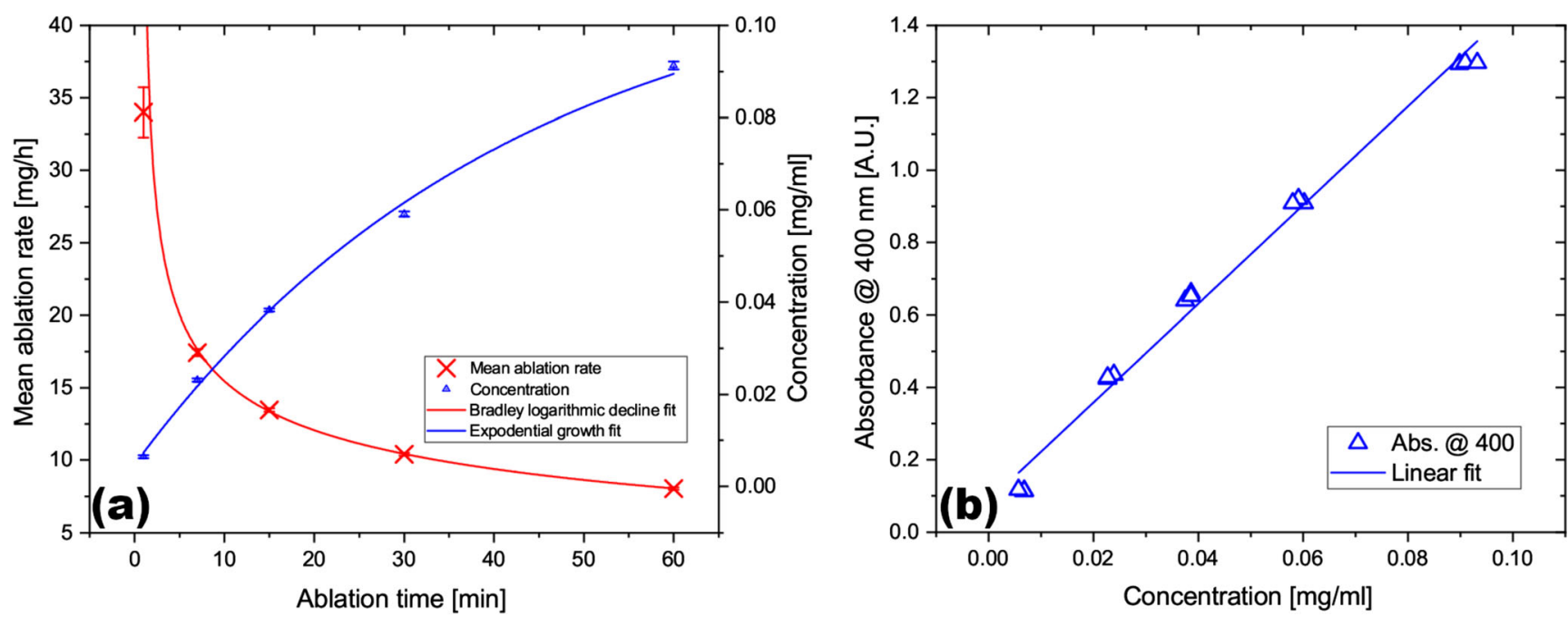

Fig. 9 a Ablation rate versus ablation time and concentration over $60 \mathrm{~min}$ in recirculation production, $(\mathrm{n}=3)$ and $\mathbf{b}$ absorbance versus concentration where concentration was linearly fit to absorbance measurements (adjusted $\mathrm{R}^{2}=0.989 ; n=3$ ) 


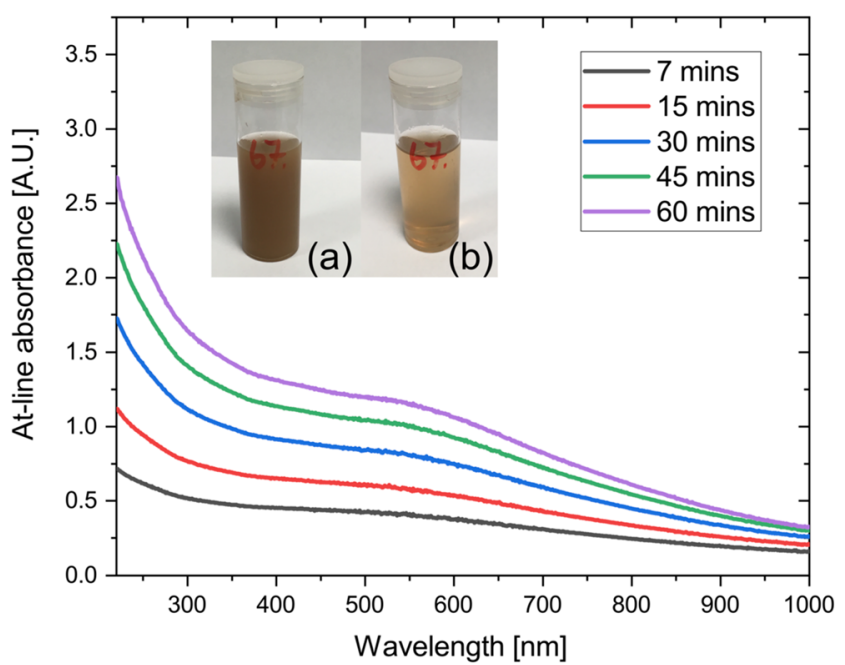

Fig. 10 At-line UV-Vis absorbance measurement of SiNps produced by up to 60 -min recirculation mode up to $60 \mathrm{~min}$ and the produced colloids after $60 \mathrm{~min}$ (inset a) as produced and (inset b) after $0.2-\mu \mathrm{m}$ filtration $(n=$ 3)

The recirculation tests show a capacity for the process to produce $83 \mathrm{ml}$ of SiNps colloid with a selectable concentration up to $91 \pm 4 \mathrm{mg} / \mathrm{L}$ in $60 \mathrm{~min}$, displaying a process variation of only $4 \%$. This concentration production compares with $6.8 \mathrm{mg} / 1$ produced via continuous modes at $50 \mathrm{ml} / \mathrm{min}$ liquid flow as illustrated in the UV-Vis spectra in Fig. 7, but at the expense of production efficiency. The concentrations produced compare well with colloids produced by Kobayashi et al. [52] who achieved $30 \mathrm{mg} / \mathrm{l}$ using a similar power laser systems (fluence $=0.6 \mathrm{~J} / \mathrm{cm}^{2}$ ) on Si targets in batch mode [52]. This operational mode provides for small volume $(<100 \mathrm{ml})$, high concentration $\mathrm{Np}$ production, suitable for the generation of thin-films towards biosensing and Np inks applications.

\subsubsection{At-line colloid monitoring on recirculatory production}

At-line UV-Vis monitoring should offer numerous process advantages when monitoring the state of the process in real-time. Its applications as a PAT tool could vary from on-line estimates of colloid concentration, identification of colloid quality, determination of spectra as characteristic of the colloid required, testing of solvent and surfactant suitability, a check if the ablation within control limits, determination of the impact of changing process conditions, and acting as early fault diagnosis. To determine at-line UV-Vis suitability to meet the requirement set out above, $60 \mathrm{~min}$ triplicate tests were carried out, measuring UV-Vis spectra at-line. The result of an at-line optical analysis can be seen in Fig. 10. The spectra are seen to be representative of SiNps; the absorbance is observed to increase with increasing processing time, indicating higher colloid concentrations. An example volume $(30 \mathrm{ml})$ of $83-$ $\mathrm{mg} / \mathrm{l} \mathrm{SiNps}$ colloid pre- and post-filtration is displayed in the inset of Fig. 10a and b. The prefiltered colloid is cloudy, indicating the presence of macroparticles, possibly due to thermal effects on the target, where the ablation threshold is lowered, and larger micro/macroparticles formed. The UVVis absorbance at $400 \mathrm{~nm}$ was employed to represent SiNps concentration as that wavelength possess the lowest absorption coefficient of DI water [5]. Therefore, any absorption increase should be due solely to SiNps. An absorbance estimate based on the off-line linear fit of gravimetrical concentration data developed in Fig. 9b. Triplicate results of at-line tests illustrated in Fig. 10 demonstrated a low process variation, with the 60-min mean UV-Vis absorbance at $400 \mathrm{~nm}=$ 1.296 (A.U.) and $\sigma=0.002$.

A selected at-line DLS measurement taken at the end of a 15-min recirculation ablation is described in Fig. 11a, compared with a $4 \mathrm{ml}$ sample of the colloid analysed off-line, pre(Fig. 11b) and post-filtration (Fig. 11c). The at-line measurement displays two modal peaks; peak 1 at $72.9 \pm 40 \mathrm{~nm}(65 \%$ of vol.) and peak 2 at $198 \pm 94 \mathrm{~nm}$ (35\% of vol.), whereas both off-line samples shown a singular peak distribution, off-line peak at $70 \pm 32 \mathrm{~nm}$ and filtered at $53 \pm 22 \mathrm{~nm}$. The at-line results indicate that macroparticle formation is taking place in the process, this is not seen in the off-line measurements, possibility due to the time-delay allowing larger particle sedimentation to take place. The macroparticle peak displayed in the at-line measurement may not contribute to $35 \%$ of the population volume as described by the DLS data; as with the heterodyne measurement process [37] it is usual for larger particles to mask smaller ones and in doing so, the instrument reports a larger size population weighting [53].

The primary peak at $70 \mathrm{~nm}$ is seen in all measurements and validated by TEM imaging as seen in Fig. 12 for 15-min recirculation ablation. The image was analysed using the ImageJ software, and the peak diameter was observed at 70 $\pm 90 \mathrm{~nm}$ (full width half max). This is slightly higher than that (a). At-line

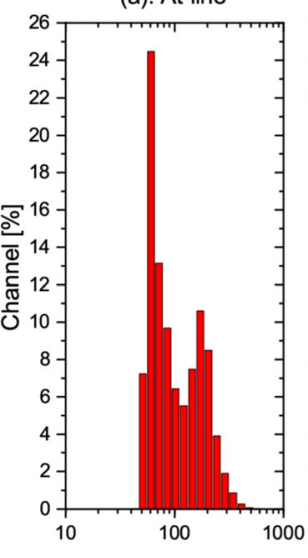

(b). Off-line

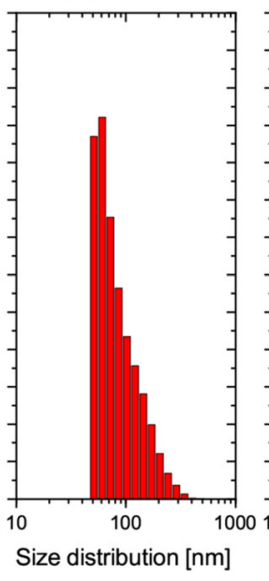

(c). Filtered off-line

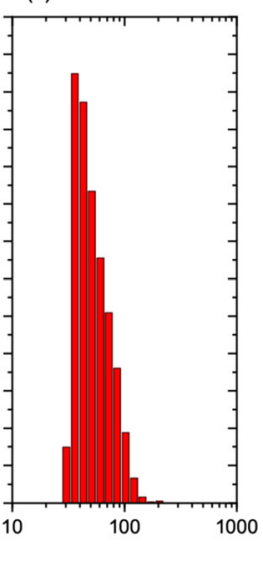

Fig. 11 DLS size distributions of SiNps in DI water after 15 min of recirculation production as measured (a) at-line, (b) off-line and (c) offline after a $200-\mathrm{nm}$ filtration 
of the filtered off-line DLS measurement which is considered to be due to the difference in measurement techniques and that the DLS analysis would sample a larger representative colloid volume.

\subsection{Validation of process analytical tools}

UV-Vis spectroscopy is a common nanocolloid optical characterisation method, which is used to discuss LASiS produced colloid quality. In this work, we have discussed the application of an at-line measurement approach. Here, the efficiency of its measurement against a larger data set $(n=27)$, covering different operational modes (recirculation/continuous) and colloid concentrations are examined. At-line measurements are compared with the standard off-line measurement approach. A linear correlation between at-line measurement and off-line was observed with an adjusted $R^{2}$ of 0.993 , as seen in Fig. 13. The slope displayed almost parity of measurement (1.070). A 90\% confidence interval of the predication (at-line) was applied to the linear fit. All at-line measurements are deemed to be in control and representative of the off-line, falling within the $90 \%$ confidence interval ( $t$-distribution) of the linear fit.

To validate the at-line DLS process monitoring, a series of recirculation experiments were implemented with at-line DLS measurement performed after laser irradiation was complete. Results of the peak diameter process means for at-line, off-line and filtered measurements are illustrated in Fig. 14, where a $1 \sigma$ overlap of at-line and off-line measurements is observed. A Student $t$-test performed on the data showed with a $90 \%$

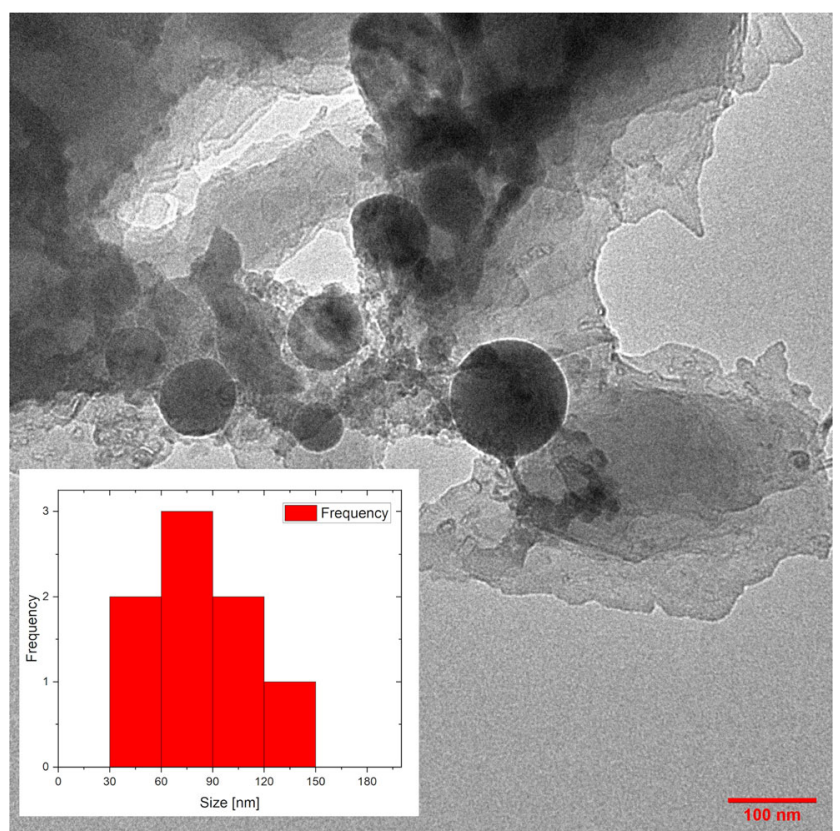

Fig. 12 TEM micrograph of SiNps produced via recirculation mode and (inset) size determined via image analysis

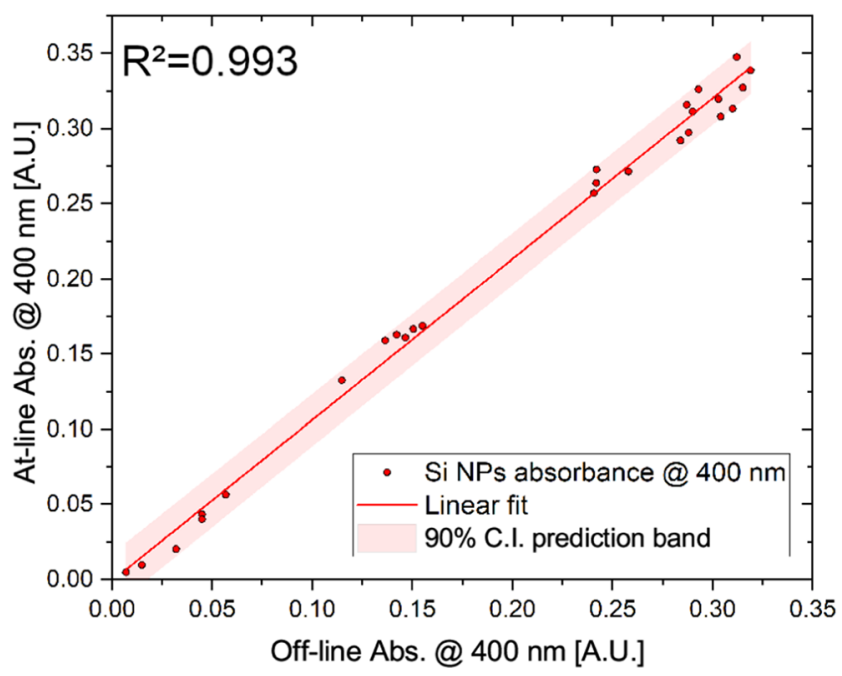

Fig. 13 Comparison of at-line and off-line UV-Vis measurements over a range of 0 to 0.35 A.U. $(n=27)$

confidence level, that at-line and off-line means had no significant difference (standard error of mean $=8 \mathrm{~nm}$ ). Consequently, using the null hypothesis, it can be concluded that at-line size analysis is a viable measurement configuration, in agreement with the standard off-line DLS measurement approach. It should be noted that from the individual size distribution measurement in Fig. 15 and the mean process data in Fig. 14 the at-line measurement displays larger peak diameters compared with off-line, with the difference in measurement reducing after $7 \mathrm{~min}$.

\subsubsection{At-line recirculation size monitoring tool}

To utilise the DLS as an at-line monitoring tool, 60-min ablation tests $(n=3)$ were performed monitoring the SiNps size at-

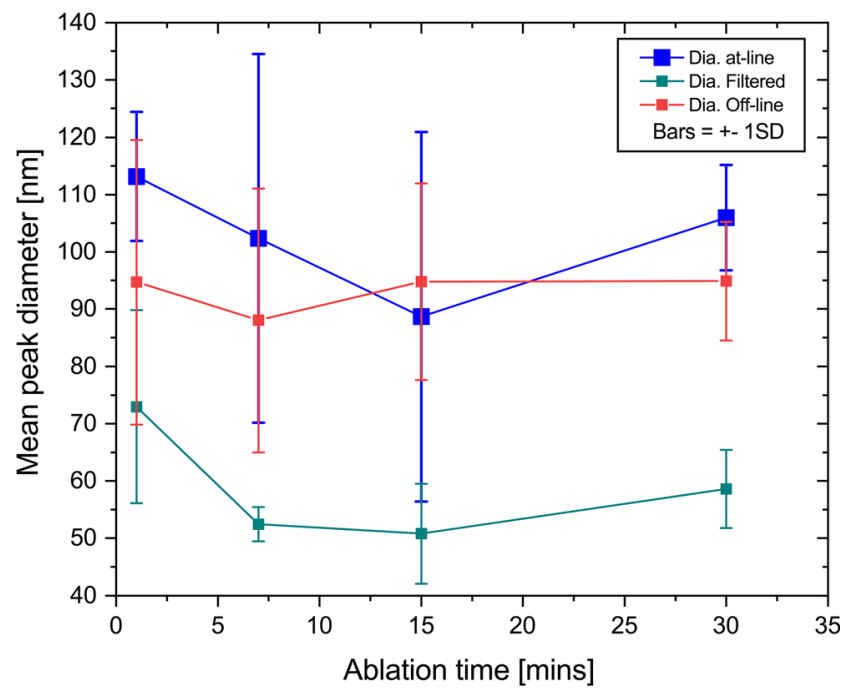

Fig. 14 Nps mean peak diameter versus ablation time as measured atline, off-line and off-line post 200-nm filtration in recirculation mode. Error bars signify $\pm 1 \sigma$ of mean peak diameter $(n=3)$ 


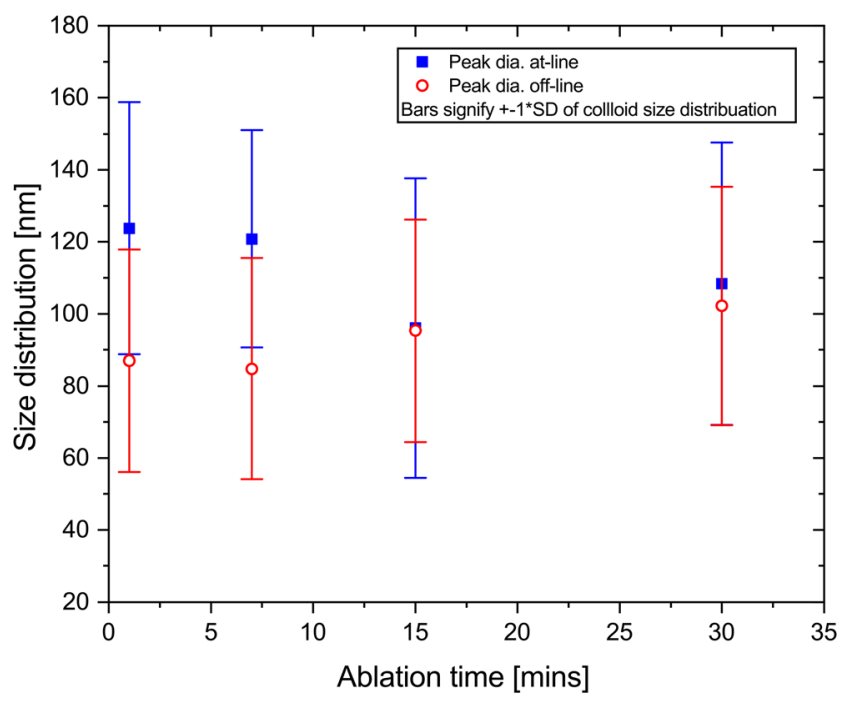

Fig. 15 Comparison of at-line and off-line measurements of Np peak diameters up to 30 -min ablation time during recirculation mode, including size population width $( \pm 2 \sigma),(n=1)$

line. The individual colloid peak diameter and distribution width $(2 \sigma)$ is illustrated in Fig. 16, and plotted alongside the process mean $(\bar{x}=103 \mathrm{~nm})$ and process standard deviation $(\sigma=24 \mathrm{~nm})$, for the three runs. For the tests the peak diameters are largely within $1 \sigma$ of the process mean for the majority of measurements taken, indicating that the ablation process is in control. However, a process change is indicated in the 15- to 30-min ablation timeframe, where the peak diameters approach or cross the $1 \sigma$ control limit. This process change may be due to thermal effects on the target or colloid settling taking place. Lower concentration colloids may also be more susceptible to machine vibrations interfering with the measurement. Nanoparticle size has been previously seen to be a function of laser fluence [41] and pulse overlap [54] as the laser conditions remained constant for the tests performed and the resultant peak diameter stayed within one standard deviation from the mean, it can be assumed that there was no significance change in the process conditions during the test period.

Given that the process recirculates the Nps colloid within the flow-cell, the possibility of photo fragmentation should be considered; however, a trend of size reduction with time was not observed. This observation is in alignment with the hypothesis that minimal photofragmentation of the SiNps should occur under $1064 \mathrm{~nm}$ irradiation $[19,21]$ as the absorption
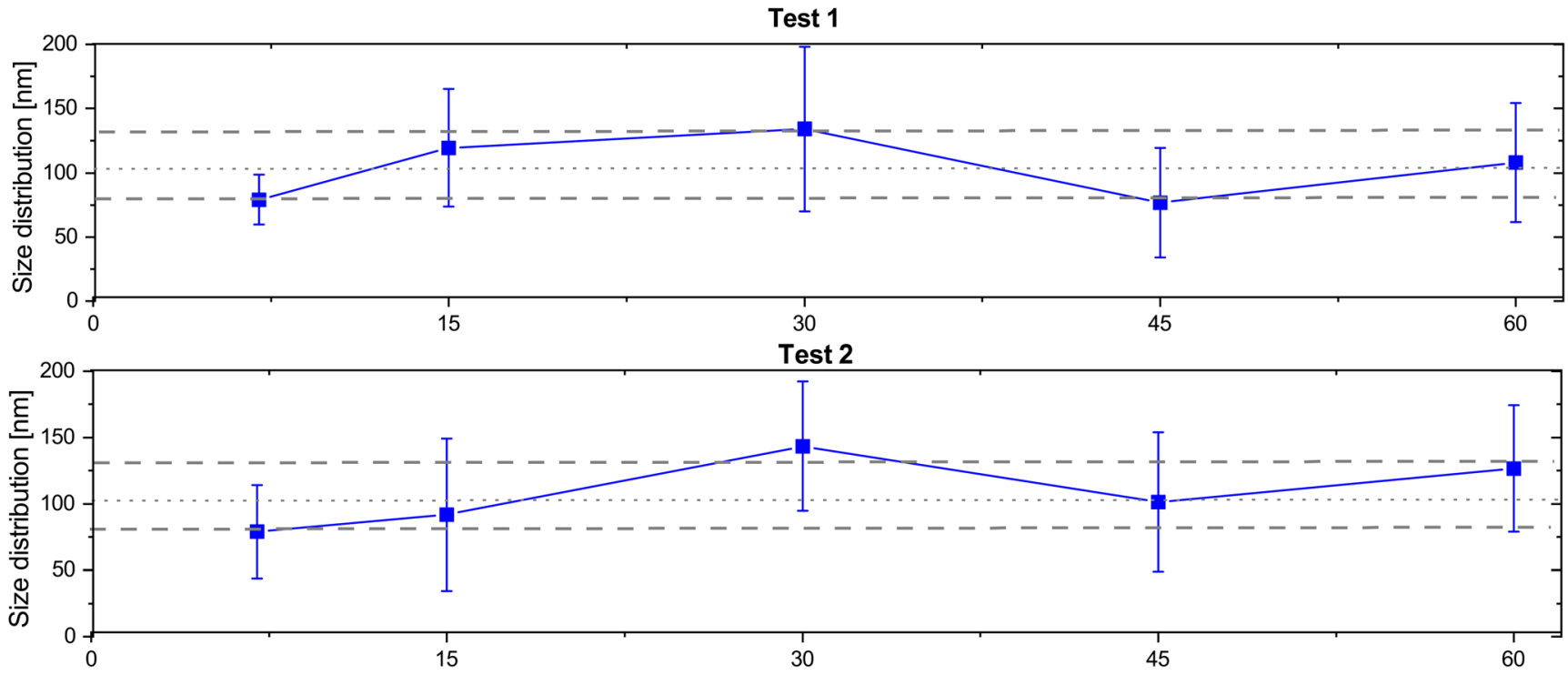

Test 3

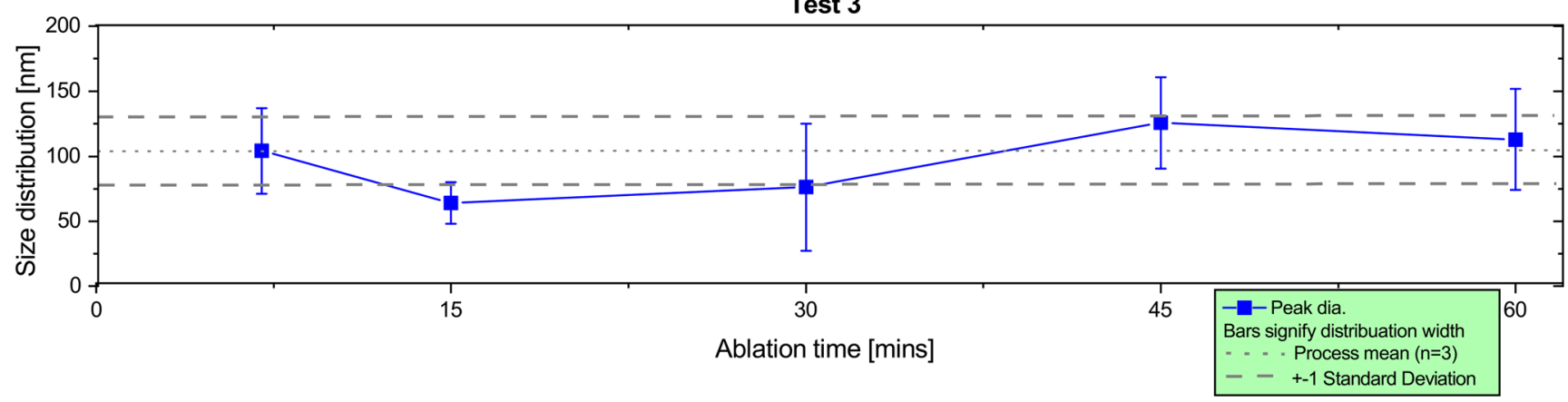

Fig. 16 Size distribution of SiNps measured via DLS at-line for up to $60 \mathrm{~min}$ ablation in recirculation mode 
coefficient of the SiNps is relatively low at the Nd:YAG fundamental wavelength when compared with, the frequencydoubled $532 \mathrm{~nm}$ [52] where the absorption coefficient is two order of magnitudes greater. This analysis demonstrates that Si colloids can be manufactured to repeatable size distributions independent of colloid concentration and process time. As discussed previously it is expected that the at-line measurements will measure slightly higher than off-line measurement, but the at-line monitoring can prove a useful insight into the process, and in the future could act as the primary colloid production control and validation step.

\section{Conclusions}

In summary, this work has focused on implementing highly efficient laser ablation to improve $\mathrm{Np}$ fabrication productivity and presents a new Nps fabrication system, which reduces the complexity of the LASiS technique by implementing automation and PAT tools, helping to promote the adoption of LASiS in several research fields. Rapid prototyping was utilised to produce a laminar flow environment within the flow cell. This system has demonstrated higher SiNps production efficiencies of $34 \mathrm{mg} /$ Wh, higher than reported to date $[29,55,56]$ by optimising flow conditions within the flow cell, while providing control of colloid concentration via solvent flow in continuous mode and by production time in recirculation mode. Furthermore, this work also included:

- First demonstration of DLS integration in a laser-based Np production process

- Integration of commercial monitoring tools into Np production system capable of monitoring colloid production at rates up to $170 \mathrm{ml} / \mathrm{min}$.

- Online measurements were statistically similar to off-line monitoring and provides real-time information of the production process

- Colloid concentration controlled via solvent flow in continuous mode and production time in recirculation mode

- Highest reported power-specific productivity rate reported to-date for a laser-based $\mathrm{Np}$ production process of 12.9 $\mathrm{mg} / \mathrm{Wh}$

Supplementary Information The online version contains supplementary material available at https://doi.org/10.1007/s00170-021-06772-6.

Funding This publication has emanated from research supported the School of Biotechnology, Dublin City University and by research grants from Science Foundation Ireland (SFI) under Grant Number 12/IA/1576 and Grant 16/RC/3872 and is co-funded under the European Regional Development Fund and by I-Form industry partners, and from the
European Union's Horizon 2020 research and innovation programme under grant agreement No. 862000.

Data availability Data files are available online: https://doi.org/10.17632/ m48784x79n.1.

Code availability Not applicable

\section{Declarations}

Ethical approval Not applicable

Consent to participate Not applicable

Consent to publish Not applicable

Competing interests The authors declare that they have no known competing financial interests or personal relationships that could have influenced the work reported in this paper.

\section{References}

1. Bagheri E, Ansari L, Abnous K, Taghdisi SM, Charbgoo F, Ramezani M, Alibolandi M (2018) Silica based hybrid materials for drug delivery and bioimaging. J Control Release 277:57-76

2. Fathi F, Rashidi M-R, Omidi Y (2018) Talanta ultra-sensitive detection by metal nanoparticles-mediated enhanced SPR biosensors. Talanta 192(September 2018):118-127

3. Silva A, Amaral M, Sousa Lobo J, Lopes C (2016) Lipid nanoparticles for the delivery of biopharmaceuticals. Curr Pharm Biotechnol 16(999):1-1

4. Rehbock C, Jakobi J, Gamrad L, van der Meer S, Tiedemann D, Taylor U, Kues W, Rath D, Barcikowski S (2014) Current state of laser synthesis of metal and alloy nanoparticles as ligand-free reference materials for nano-toxicological assays. Beilstein $J$ Nanotechnol 5(1):1523-1541

5. Vasiliev M, Alameh K (2008) Photonic nano-structures for water quality monitoring. In: Sampson DD (ed) 19th Int Conf Opt Fibre Sensors. p 70045E

6. Sreenilayam SP, Ahad IU, Nicolosi V, Acinas Garzon V, Brabazon D (2020) Advanced materials of printed wearables for physiological parameter monitoring. Mater Today 32:147-177

7. Petriev VM, Tischenko VK, Mikhailovskaya AA, et al (2019) Nuclear nanomedicine using Si nanoparticles as safe and effective carriers of 188 Re radionuclide for cancer therapy. Sci Rep 9:1-10

8. Angelov SD, Koenen S, Jakobi J, Heissler HE, Alam M, Schwabe K, Barcikowski S, Krauss JK (2016) Electrophoretic deposition of ligand-free platinum nanoparticles on neural electrodes affects their impedance in vitro and in vivo with no negative effect on reactive gliosis. J Nanobiotechnology 14:3

9. Mahvi DA, Liu R, Grinstaff MW, Colson YL, Raut CP (2018) Local Cancer Recurrence: The Realities, Challenges, and Opportunities for New Therapies. CA Cancer J Clin 68:488-505

10. Marison I, Hennessy S, Foley R, Schuler M, Sivaprakasam S, Freeland B (2013) The choice of suitable online analytical techniques and data processing for monitoring of bioprocesses. $A d v$ Biochem Eng Biotechnol 132:249-280

11. Jendrzej S, Gökce B, Epple M, Barcikowski S (2017) How size determines the value of gold: economic aspects of wet chemical and laser-based metal colloid synthesis. ChemPhysChem 18(9):10121019 
12. Stavropoulos P, Stournaras A, Salonitis K, Chryssolouris G (2010) Experimental and theoretical investigation of the ablation mechanisms during femptosecond laser machining. Int J Nanomanuf 6(14):55-65

13. Tomko J, O'Malley SM, Trout C, Naddeo JJ, Jimenez R, Griepenburg JC, Soliman W, Bubb DM (2017) Cavitation bubble dynamics and nanoparticle size distributions in laser ablation in liquids. Colloids Surf A Physicochem Eng Asp 522:368-372

14. Lam J, Lombard J, Dujardin C, Ledoux G, Merabia S, Amans D (2016) Dynamical study of bubble expansion following laser ablation in liquids. Appl Phys Lett 108(7):1-6

15. Barcikowski S, Amendola V, Marzun G, Rehbock C, Reichenberger S, Zhang D, Gökce B (2016) Handbook of Laser Synthesis of Colloids

16. He C, Sasaki T, Usui H, Shimizu Y, Koshizaki N (2007) Fabrication of $\mathrm{ZnO}$ nanoparticles by pulsed laser ablation in aqueous media and $\mathrm{pH}$-dependent particle size: an approach to study the mechanism of enhanced green photoluminescence. $J$ Photochem Photobiol A Chem 191(1):66-73

17. Intartaglia R, Barchanski A, Bagga K, Genovese A, Das G, Wagener P, di Fabrizio E, Diaspro A, Brandi F, Barcikowski S (2012) Bioconjugated silicon quantum dots from one-step green synthesis. Nanoscale 4(4):1271-1274

18. Bagga K, Barchanski A, Intartaglia R, Dante S, Marotta R, Diaspro A, Sajti CL, Brandi F (2013) Laser-assisted synthesis of Staphylococcus aureus protein-capped silicon quantum dots as bio-functional nanoprobes. Laser Phys Lett 10:065603

19. Bagga K, McCann R, O'Sullivan F, Ghosh P, Krishnamurthy S, Stalcup A, Vázquez M, Brabazon D (2017) Nanoparticle functionalized laser patterned substrate: an innovative route towards low cost biomimetic platforms. RSC Adv 7(13):8060-8069

20. Bagga K, McCann R, Brasi Q, Coussy J, Stalcup A, Vázquez M, Brabazon D (2016) Laser-assisted synthesis of ultrapure nanostructures for biological sensing applications. In: Kobayashi N, Ouchen F, Rau I (eds) Proc. SPIE. Nanobiosystems: Processing, Characterization, and Applications IX, San Diego, CA., p 992800

21. Intartaglia R, Bagga K, Brandi F (2014) Study on the productivity of silicon nanoparticles by picosecond laser ablation in water: towards gram per hour yield. Opt Express 22(3):3117

22. FDA (2011) Guidance for industry process validation: General principles and practices

23. FDA (2017) Advancement of emerging technology applications for pharmaceutical innovation and modernization guidance for industry

24. Freeland B, McCann R, O’Neill P, Bagga K, Foley G, Brabazon D (2019) Flow-regime and laser wavelength optimization of Silicon Nanoparticle fabrication via laser ablation synthesis in solution ( LASiS ). 22nd Sir Bernard Crossl Symp

25. Streubel R, Barcikowski S, Gökce B (2016) Continuous multigram nanoparticle synthesis by high-power, high-repetition-rate ultrafast laser ablation in liquids. Opt Lett 41(7): 1486

26. Freeland B, McCann R, Foley G, Brabazon D (2020) Highefficiency generation of nanomaterials via laser ablation synthesis in solution with in-situ diagnostics for closed-loop control. In: Kabashin A V., Dubowski JJ, Geohegan DB (eds) Synth. Photonics Nanoscale Mater. XVII. SPIE, p 112690M

27. Dittrich S, Streubel R, McDonnell C, Huber HP, Barcikowski S, Gökce B (2019) Comparison of the productivity and ablation efficiency of different laser classes for laser ablation of gold in water and air. Appl Phys A Mater Sci Process 125(6):1-10

28. Brignoli Y, Freeland B, Cunningham D, Dabros M (2020) Control of specific growth rate in fed-batch bioprocesses: novel controller design for improved noise management. Processes 8(6):679

29. Wagener $P$ et al (2017) High productive and continuous nanoparticle fabrication by laser ablation of a wire-target in a liquid jet. Appl Surf Sci 403:487-499
30. Crivellaro S, Guadagnini A, Arboleda DM, Schinca D, Amendola V (2019) A system for the synthesis of nanoparticles by laser ablation in liquid that is remotely controlled with PC or smartphone. Rev Sci Instrum 90:033902

31. Wagener P, Schwenke A, Chichkov BN, Barcikowski S (2010) Pulsed laser ablation of zinc in tetrahydrofuran: bypassing the cavitation bubble. J Phys Chem C 114(17):7618-7625

32. Barcikowski S, Mafuné F (2011) Trends and current topics in the field of laser ablation and nanoparticle generation in liquids. $J$ Phys Chem C 115(12):4985

33. Bikas H, Stavropoulos P, Chryssolouris G (2016) Additive manufacturing methods and modeling approaches: a critical review. Int J Adv Manuf Technol 83(1-4):389-405

34. Stratasys (2015) VeroWhitePlus polyjet technology material specifications

35. DuPont Fluoroproducts, Dupont (1996) Teflon PTFE fluoropolymer resin: properties handbook

36. Boyes W (2011) Instrumentation reference book. ButterworthHeinemann/Elsevier, Amsterdam

37. Plantz PE (2008) Explanation of data reported by microtrac instruments.

38. Blume P (2010) The labView style book. Prentice Hall, Upper Saddle River, NJ

39. National Instruments (2003) LabVIEW development guidelines.

40. Haidary SM, Córcoles EP, Ali NK (2012) Nanoporous silicon as drug delivery systems for cancer therapies. J Nanomater 2012:1-15

41. Kabashin A V., Meunier M (2003) Synthesis of colloidal nanoparticles during femtosecond laser ablation of gold in water. J Appl Phys 94:7941

42. Freeland B, McCann R, Alkan G, Friedrich B, Foley G, Brabazon D (2020) Stable nano-silver colloid production via Laser Ablation Synthesis in Solution (LASiS) under laminar recirculatory flow. Adv Mater Process Technol 6:677-685

43. Kudryashov SI, Nastulyavichus AA, Ivanova AK, et al (2019) High-throughput laser generation of Si-nanoparticle based surface coatings for antibacterial applications. Appl Surf Sci 470:825-831

44. Polyanskiy MN Refractive index database. https://refractiveindex. info. Accessed 18 Mar 2020

45. Zhang D, Gökce B, Barcikowski S (2017) Laser synthesis and processing of colloids: fundamentals and applications. Chem Rev 117(5):3990-4103

46. Kudryashov SI, Samokhvalov AA, Nastulyavichus AA, Saraeva IN, Mikhailovskii VY, Ionin AA, Veiko VP (2019) Nanosecondlaser generation of nanoparticles in liquids: From ablation through bubble dynamics to nanoparticle yield. Materials (Basel) 12:1-15

47. Brand AA, Meyer F, Nekarda J-F, Preu R (2014) Reduction of picosecond laser ablation threshold and damage via nanosecond pre-pulse for removal of dielectric layers on silicon solar cells. Appl Phys A 117:237-241

48. Thorstensen J, Erik Foss S (2012) Temperature dependent ablation threshold in silicon using ultrashort laser pulses. J Appl Phys 112:10

49. Barcikowski S, Gökce B, Marzun G (2016) "Process-stable, highly pure nanomaterials for energy research made by scalable, continuous laser production.” 3022(2013):11928

50. Reich S, Schönfeld P, Wagener P, Letzel A, Ibrahimkutty S, Gökce B, Barcikowski S, Menzel A, dos Santos Rolo T, Plech A (2017) Pulsed laser ablation in liquids: impact of the bubble dynamics on particle formation. J Colloid Interface Sci 489:106-113

51. Intartaglia R, Bagga K, Brandi F, Das G, Genovese A, di Fabrizio E, Diaspro A (2011) Optical properties of femtosecond lasersynthesized silicon nanoparticles in deionized water. $J$ Phys Chem C 115(12):5102-5107

52. Kobayashi $\mathrm{H}$, Chewchinda $\mathrm{P}$, Ohtani $\mathrm{H}$, Odawara $\mathrm{O}$, Wada $\mathrm{H}$ (2013) Effects of laser energy density on silicon nanoparticles produced using laser ablation in liquid. J Phys Conf Ser 441:012035 
53. Tomaszewska E, Soliwoda K, Kadziola K, Tkacz-Szczesna B, Celichowski G, Cichomski M, Szmaja W, Grobelny J (2013) Detection limits of DLS and UV-Vis spectroscopy in characterization of polydisperse nanoparticles colloids. J Nanomater 2013:1-10

54. Barcikowski S, Hahn A, Kabashin AV, Chichkov BN (2007) Properties of nanoparticles generated during femtosecond laser machining in air and water. Appl Phys A Mater Sci Process 87(1):4755
55. Cenide D, Streubel R, Bärsch N, Barcikowski S (2012) Advanced liquid flow reactor design for laser ablation in liquid Motivation. In: 2nd Conf. Laser Ablation Nanoparticle Gener. Liq. Taormina, p 29

56. Streubel R, Bendt G, Gökce B (2016) Pilot-scale synthesis of metal nanoparticles by high-speed pulsed laser ablation in liquids. Nanotechnology 27:205602

Publisher's note Springer Nature remains neutral with regard to jurisdictional claims in published maps and institutional affiliations. 